\title{
The Burden of Rheumatic Diseases: An Analysis of an Italian Administrative Database
}

\author{
Sergio Iannazzo • Gianluca Furneri · Federica Demma · Chiara Distante • \\ Simone Parisi · Veronica Berti · Enrico Fusaro
}

Received: April 11, 2016/ Published online: May 26, 2016

(C) The Author(s) 2016. This article is published with open access at Springerlink.com

\begin{abstract}
Introduction: Chronic inflammatory rheumatic diseases (RDs) trigger high costs for healthcare systems and society due to the disability and comorbidity associated with these disease entities. The aim of this study was to analyze patients with $\mathrm{RD}$, assess the use of conventional synthetic and biologic therapies, and estimate the overall cost of treatment in Italy.
\end{abstract}

Methods: Administrative healthcare claims from the Piedmont region in Northwest Italy were reviewed to identify patients who received disease-modifying antirheumatic drugs

Enhanced content To view enhanced content for this article go to www.medengine.com/Redeem/22D4F0602 802F8AA.

S. Iannazzo $(\bowtie) \cdot C$. Distante

SIHS Health Economics Consulting, Turin, Italy

e-mail: sergio.iannazzo@icloud.com

G. Furneri · F. Demma

EBMA Consulting, Milan, Italy

S. Parisi · E. Fusaro

Rheumatology Department, Azienda

Ospedaliero-Universitaria Città della Salute e della

Scienza di Torino, Turin, Italy

V. Berti

CSI, Turin, Italy
(DMARDs) between 2007 and 2010. Confirmation of RD was based on: (1) diagnosis-specific exemption code; (2) hospitalization or emergency care events characterized by disease-specific ICD9 codes; (3) inclusion in the regional registry of biologic drugs. The follow-up period was 3 years.

Results: A total of 9560 subjects, of whom the majority were women (58.1\%), were entered into the study; the average age of the study population was 55.3 years. On the index date $12.9 \%$ of patients were receiving a biologic DMARD, with adalimumab the most frequently prescribed biologic DMARD (4.7\%), followed by etanercept (4.4\%). The average total healthcare expenditure was $€ 377.98$ per patient per month (patient-month). In the subgroup analysis of healthcare costs according to use of biologics, the total expenditure was $€ 1037.97 /$ $€ 230.86$ patient-month for those receiving/not receiving at least one biologic DMARD. In the subgroup analysis of healthcare costs according to type of biologic used, the total expenditure ranged from $€ 657.61$ (golimumab) to $€ 1384.15$ (rituximab) patient-month.

Conclusions: A substantial difference in the total costs according to treatment/no 
treatment with a biologic and the specific biologic DMARD prescribed was identified. However, this result should be interpreted with caution as a bias in terms of patient selection was most likely present. The results of this study shed some light on RD in an relevant sample of Italian patients. The preliminary conclusions need to be confirmed by further analysis.

Keywords: Antirheumatic drugs; Biologics; Burden of disease; Italy; Rheumatic diseases

\section{INTRODUCTION}

Inflammatory rheumatic diseases (RDs) in general and rheumatoid arthritis, psoriatic arthritis, and ankylosing spondylitis specifically are chronic systemic disorders which significantly affect patients' quality of life. These pathologies are debilitating and progressive and are associated with severe functional impairment and pain $[1,2]$. The worldwide prevalence of RDs is high (about 1\%) [3-6], with rheumatoid arthritis alone accounting for $0.3-1 \%$ of all RDs identified [7].

First-line treatments for inflammatory RDs include non-steroidal anti-inflammatory drugs, conventional disease-modifying anti-rheumatic drugs (DMARDs; e.g., methotrexate), and corticosteroids; immunosuppressants and systemic corticosteroids are also used [8-13]. In the last 15 years the development of biologic drugs, such as infliximab, etanercept, adalimumab, certolizumab, golimumab, tocilizumab, rituximab, anakinra, abatacept, and ustekinumab, has resulted in a significant improvement in the prognosis of rheumatic patients. Patients who are intolerant to the chosen treatment or show an inadequate response (IR) to traditional synthetic DMARDs are often treated with a biologic drug [14-17]. The treatment of rheumatic patients with an IR to DMARDs alone usually consists of combination therapy with a biologic and traditional DMARD, primarily methotrexate; however, a number of biologics have been shown to be efficacious and approved for monotherapy [18-20].

The aim of this study was to analyze the characteristics of patients with rheumatoid arthritis, psoriatic arthritis, and ankylosing spondylitis in Italy, assess the use of conventional synthetic and biologic DMARDs, and estimate the overall cost of managing these patients within the framework of the Italian National Health Service (NHS).

\section{METHODS}

The data for this analysis was based on the administrative healthcare claims of the Piedmont region, which is located in Northwest Italy and is the second largest administrative region by area in Italy and the sixth largest by number of inhabitants (about 4.4 million) [21]. Due to the administrative nature of the data used, all data was de-identified, and no clinical or personal information was available.

An information network is maintained in each Italian administrative region that routinely records the healthcare expenditures for services covered by the NHS. The pharmaceutical registry for each region routinely records the costs of dispensing drugs to those registered in the system. Data available for each prescription claim include the patient's national health number, the Anatomical Therapeutic Chemical Classification System code (ATC) [22] of the drug dispensed, the number of packages dispensed, the number of 
units per package, the dose, the unit cost per package, and the prescription date. The outpatient services registry tracks all laboratory investigations, instrumental tests, and specialist visits. These databases were analyzed along with the database of hospital admissions (SDO), emergency care and the regional registry of biologic drugs in rheumatology. The RDs considered were rheumatoid arthritis, psoriatic arthritis and ankylosing spondylitis. The study population was identified as patients who received at least one prescription of a synthetic or biologic DMARD during the period between 1 January 2007 and 31 December 2010. The first prescription represented the index date for each patient.

The biologic drugs considered in the study were: etanercept (ATC: L04AB01), infliximab (ATC: L04AB02), adalimumab (ATC: L04AB04), certolizumab (ATC: L04AB05), golimumab (ATC: L04AB06), tocilizumab (ATC: L04AC07), rituximab (ATC: L01XC02), anakinra (ATC: L04AC03), abatacept (ATC: L04AA24), and ustekinumab (ATC: L04AC05).

The synthetic DMARDs considered were: methotrexate (ATC: L01BA01; L04AX03), azathioprine (ATC: L04AX01), leflunomide (ATC: L04AA13), sulfasalazine (ATC: A07EC01), and hydroxychloroquine (ATC: P01BA02).

The data were analyzed with the aim to link subjects to a diagnosis of the $\mathrm{RD}$ of interest (rheumatoid arthritis, psoriatic arthritis, ankylosing spondylitis). For a diagnosis of the target $\mathrm{RD}$, at least one of the following criteria had to be met: (1) diagnosis-specific exemption code; (2) hospitalization or emergency care events marked with disease-specific ICD9 codes (696.0 and 696.1 for psoriatic arthritis; 714.0, 714.1, 714.2, 714.30, 714.32, and 714.33 for rheumatoid arthritis; 720.0 for ankylosing spondylitis) (3) inclusion in the special rheumatology registry of biologic drugs. In addition, patients who received at least one prescription of methotrexate or leflunomide in the 3 years of analysis were considered to be rheumatic patients and included in the analysis.

Patient data were anonymously linked and imported into STATA version 13.1 (StataCorp, College Station, TX), and clinical (comorbidity), pharmacological (treatment pattern), and economic (total healthcare costs) indicators were analyzed. Each patient was followed from the index date up to 3 years. The total healthcare cost was estimated taking drug prescription (synthetic and biologic DMARDS and co-medications), hospital, and outpatient costs into account. The cost analysis was developed for the entire population and also for subgroups of patients identified on the basis of biologic DMARD use.

\section{RESULTS}

In total, 12,455 subjects with at least one prescription for a synthetic or biologic DMARD was identified in the period 2007-2010. Of these, 2895 subjects were excluded because they did not meet any of the conditions required for a confirmed RD. The category of indistinct RD was defined to include those cases in which, despite the certainty of the presence of $\mathrm{RD}$, it was not possible to assign the condition to one of the three rheumatic diseases of interest. This category included patients with a discordant definition of more than one disease of interest $(n=584 ; 4.7 \%)$, those who were identified as RD patients only on the basis of a prescription for methotrexate ( $n=710 ; 5.7 \%)$, and those with juvenile idiopathic arthritis $(n=6 ; \approx 0.0 \%)$. Following exclusion of those who did not meet the inclusion criteria, the overall study population 
consisted of 9560 patients, among whom 1855 had psoriatic arthritis (19\%), 5989 had rheumatoid arthritis (63\%), and 416 had ankylosing spondylitis (4\%). The majority of patients were women $(58.1 \%)$, and the mean [ \pm standard deviation (SD)] age of the study population was $55.3( \pm 17.4)$ years. The analysis of presence of comorbidity in the study population $(N=9560)$ is shown in Table 1 .

Of the 9560 patients entered into the study, 4153 (43\%) reported at least one hospitalization between the index date and the end of the 3-year observation period, among whom were 2655 of the 5989 patients with rheumatoid arthritis (44\%), 149 of the 416 patients with ankylosing spondylitis (36\%), and 651 of the 1885 patients with psoriatic arthritis (35\%). Of the 1300 patients diagnosed with indistinct RD, 698 (54\%) reported at least one hospitalization during the index date and the end of the 3-year observation period.

On the index date $12.9 \%$ of the study population were receiving a biologic DMARD. The distribution of all prescriptions on the index date is shown in Table 2. The total study population of 9560 patients received 9963 prescriptions in the first year (some patients received more $>1$ biologic DMARD). The

Table 1 Comorbidities in the study population $(n=9560)$

\begin{tabular}{|c|c|c|c|}
\hline Comorbidity & $\begin{array}{l}\text { Patients } \\
(n)\end{array}$ & $\begin{array}{l}\text { Percentage of patients } \\
\text { in the overall study } \\
\text { population }(n=9560) \\
\text { with a specific } \\
\text { comorbidity }\end{array}$ & $\begin{array}{l}\text { Percentage of patients } \\
\text { with a comorbidy } \\
\text { with } \geq 1 \text { hospitalization } \\
(n=4153)\end{array}$ \\
\hline Cardiopathy & 43 & 0.45 & 1.04 \\
\hline Conduction disorders & 37 & 0.39 & 0.89 \\
\hline Arrhythmias & 253 & 2.65 & 6.09 \\
\hline Heart failure & 153 & 1.60 & 3.68 \\
\hline Other undefined heart diseases & 48 & 0.50 & 1.16 \\
\hline Myocardial infarction & 87 & 0.91 & 2.09 \\
\hline $\begin{array}{l}\text { Other acute and subacute forms of } \\
\text { ischemic heart disease }\end{array}$ & 62 & 0.65 & 1.49 \\
\hline Previous myocardial infarction & 73 & 0.76 & 1.76 \\
\hline Angina pectoris & 52 & 0.54 & 1.25 \\
\hline Other forms of ischemic heart disease & 151 & 1.58 & 3.64 \\
\hline Cerebrovascular disease & 278 & 2.91 & 6.69 \\
\hline Hypercholesterolemia & 100 & 1.05 & 2.41 \\
\hline Hyperuricemia & 19 & 0.20 & 0.46 \\
\hline Infections & 332 & 3.47 & 7.99 \\
\hline Diabetes mellitus & 305 & 3.19 & 7.34 \\
\hline Neoplasms & 688 & 7.20 & 16.57 \\
\hline Obesity & 106 & 1.11 & 2.55 \\
\hline
\end{tabular}


Table 2 Number of prescriptions on the index date in the study population $(n=9560)$ according to drug

\begin{tabular}{lrc}
\hline Prescription drug & $\begin{array}{l}\text { Prescriptions } \\
(\boldsymbol{n})\end{array}$ & $\begin{array}{l}\text { Prevalence } \\
(\%)\end{array}$ \\
\hline Biologic DMARDs & 50 & 0.5 \\
Rituximab & 8 & 0.1 \\
Abatacept & 425 & 4.4 \\
Etanercept & 292 & 3.1 \\
Infliximab & 451 & 4.7 \\
Adalimumab & 5 & 0.1 \\
Anakinra & 1231 & 12.9 \\
Total & & \\
Synthetic DMARDs & 671 & 7.0 \\
Sulfasalazine & 4452 & 46.6 \\
Methotrexate & 126 & 1.3 \\
Azathioprine & 547 & 5.7 \\
Leflunomide & 2936 & 30.7 \\
Hydroxychloroquine & 8732 & 91.3 \\
Total & 9963 & \\
Total number prescriptions & 993 \\
\hline
\end{tabular}

$D M A R D$ Disease-modifying antirheumatic drugs

highest number of prescriptions were written for methotrexate (46.6\%) and hydroxychloroquine (30.7\%); the mostly highly prescribed biologic DMARDs were adalimumab (4.7\%) and etanercept (4.4\%). Tocilizumab, certolizumab, golimumab, and ustekinumab were not available in Italy on the index date and therefore not prescribed at that time.

The prescription of concomitant medications during the 3 years of follow-up was also analyzed, revealing that concomitant medications were used by $92.5 \%$ of the study population in follow-up year 1, 97.2\% in follow-up year 2 , and $97.5 \%$ in follow-up year 3 (Table 3). The highest number of prescriptions was for non-steroidal anti-inflammatory drugs (60.4-59.6\%) and corticosteroids (58.3-57.7\%).

The total monthly healthcare expenditure for hospitalizations, emergency care, outpatient care, and pharmacological therapy (synthetic and biologic DMARDs, concomitant drugs) was assessed for the study population during the 3 years of follow-up. The total expenditure was $€ 377.98$ per patient per month (patient-month), attributable to the costs of synthetic DMARDs (€17.03), biologic DMARDs (€149.75), concomitant medications (€61.07), emergency care (€4.55), hospitalization (€92.61), and visits (€52.96) (Table 4).

The mean cost per patient per month was analyzed in the subgroups of patients who received or did not receive at least one prescription of biologic DMARD in a specific year. During years 1,2 , and 3 of the follow-up $17.7 \%, 17.5 \%$, and $19.4 \%$ of patients, respectively, had at least one prescription for a biologic DMARD. The mean total cost per patient per month including the cost of biologics was $€ 1037.97$ ( $€ 1061.20, € 1002.23$ and $€ 1050.48$ in years 1,2 , and 3 , respectively, of the follow-up) (Fig. 1). The cost of biologic DMARDs was the most important component of this total expenditure, totaling $€ 821.54$ (€829.17, $€ 798.27$. and $€ 837.17$ in years 1,2 , and 3 , respectively, of the follow-up). The mean total cost per patient per month in the subgroup of patients who did not have prescriptions for biologic DMARDS was €230.86 (€241.25, $€ 222.58$ and $€ 228.74$ in years 1,2 , and 3 , respectively, of the follow-up). In this subgroup the cost for hospitalization was the most important component of the healthcare expenditure, totaling €94.64 (€99.42, €90.40 and $€ 94.10$ in years 1,2 , and 3, respectively, of the follow-up).

The average monthly total cost per patient was also analyzed by stratifying the cohort on 
Table 3 Prevalence of prescriptions for concomitant drugs in the study population $(n=9560)$ during the 3-year follow-up

\begin{tabular}{lcccccccc}
\hline Concomitant drugs & \multicolumn{2}{l}{ Patients $(\boldsymbol{n})$} & & \multicolumn{3}{l}{ Prevalence (\%) } \\
\cline { 2 - 3 } & Year 1 & Year 2 & Year 3 & & Year 1 & Year 2 & Year 3 \\
\hline Antihypertensives & 330 & 339 & 355 & & 3.5 & 3.7 & 3.9 \\
Hypouricemic agents & 492 & 522 & 558 & & 5.1 & 5.6 & 6.2 \\
Statins & 1128 & 1290 & 1366 & & 11.8 & 13.9 & 15.1 \\
Anti-diabetics & 733 & 798 & 845 & & 7.7 & 8.6 & 9.3 \\
Anti-coagulants & 923 & 977 & 1003 & & 9.7 & 10.5 & 11.1 \\
Anti-platelets & 1318 & 1438 & 1502 & & 13.8 & 15.5 & 16.6 \\
Non-steroidal anti-inflammatories & 5779 & 5543 & 5412 & & 60.4 & 59.7 & 59.6 \\
Analgesics & 1642 & 1750 & 1907 & & 17.2 & 18.9 & 21.0 \\
Corticosteroids & 5570 & 5278 & 5234 & 58.3 & 56.9 & 57.7 \\
\hline
\end{tabular}

the basis of the specific biologic DMARD received. In this subgroup analysis, the total cost per patient per month ranged from a low of $€ 657.61$ (golimumab) to a high of $€ 1384.15$ (rituximab) (Table 5).

\section{DISCUSSION}

Rheumatoid arthritis, psoriatic arthritis, and ankylosing spondylitis are immune-mediated inflammatory diseases that lead to severe functional impairment, pain and a significant decrease in quality of life. These pathologies determine a relevant economic burden for healthcare services because of significant epidemiological impact [3-6].

The aim of this study was to analyze the characteristics, treatment patterns, and emerging costs of rheumatic patients. In total, we identified 9560 patients who had been prescribed at least one synthetic or biologic DMARD in the period 2007-2010. The prevalence of comorbidities was generally low in the study population and similar to that reported in the general population. When the prevalence of Comorbidities was analyzed in the subgroup of patients who had at least one hospitalization during the study period, we noted that it was consistently higher, possibly indicating a correlation between the comorbid condition and need for hospital care. The most commonly prescribed DMARDs were methotrexate and hydroxychloroquine (46.6 and $30.7 \%$ of prescriptions, respectively). The use of biologic DMARDs was in general low, with only about $13 \%$ of the cohort receiving them on the index data. The most commonly prescribed biologic DMARDS were adalimumab and etanercept.

Degli Esposti and colleagues analyzed the use of healthcare resources in 1219 patients with rheumatoid arthritis, psoriatic arthritis, ankylosing spondylitis, Crohn's disease, psoriasis, and ulcerative colitis [23]. The mean age $( \pm \mathrm{SD})$ of their study population was 49.6 $( \pm 14.6)$ years, $47 \%$ were men, and all patients were treated with biologic drugs (34\% with adalimumab, 51\% with etanercept, and 15\% with infliximab). The data on these patients were derived from the administrative databases 


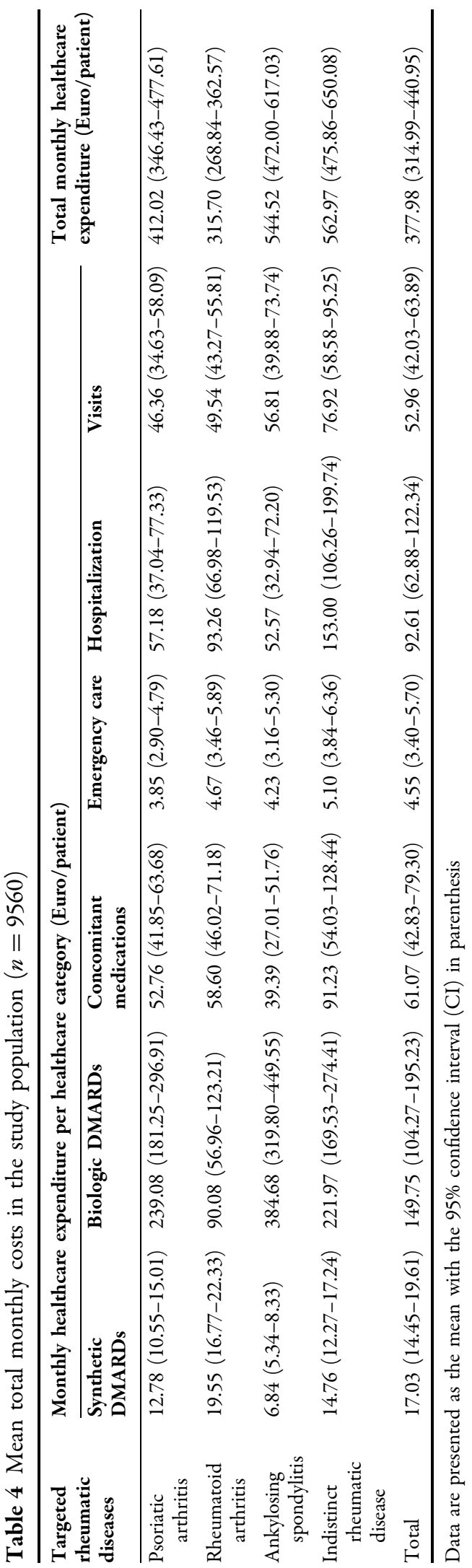

of five local health units in Italy (Emilia-Romagna, Lazio, Tuscany, Campania, and Lombardy). The analysis of these authors revealed that the overall mean annual total healthcare expenditure for each patient was of $€ 11,120$, of which non-pharmacological costs were $€ 1177$ (10.58\%) and pharmacological costs were $€ 9943$ (89.42\%). This total expenditure is significantly higher than that determined in our study population (about $€ 4500$ patient-year). One possible explanation for this difference is that the rate of use of biologic DMARDs was higher in the study of Degli Esposti et al. [23]; it may be that the cost of these drugs drove up the overall estimate. When we compare the total costs which we estimated in the subgroup of patients who received at least one prescription of biologic DMARDs (around $€ 1000$ patient-month) to the estimate of Degli Esposti and colleagues, the costs seem to be more aligned.

Based on our data it appears that a substantial difference exists in the total costs of patients treated with different biologic DMARDS, with a range of about $€ 650$ to $€ 1380$ patient-month. Beyond the effect of different prices for the different biologic DMARDS, this difference could be explained by an implicit treatment algorithm applied by the clinicians during the study period. For example, it can be assumed that only severe and difficult to treat patients who had been not responding to other classes of biologic DMARDS were prescribed rituximab-the reasoning being that this drug is not recommended as a first-line biologic in clinical guidelines. As a consequence, patients treated with rituximab in our study probably, on average, were in a more advanced stage of disease progression, had received different lines of treatment prior to being placed on rituximab, and had clinically complex disease in comparison to those treated with other 
Fig. 1 Average healthcare expenditure per patient per month according to whether a patient received or did not receive a prescription for biologic disease-modifying antirheumatic drugs (DMARDs) in a specific year of the follow-up

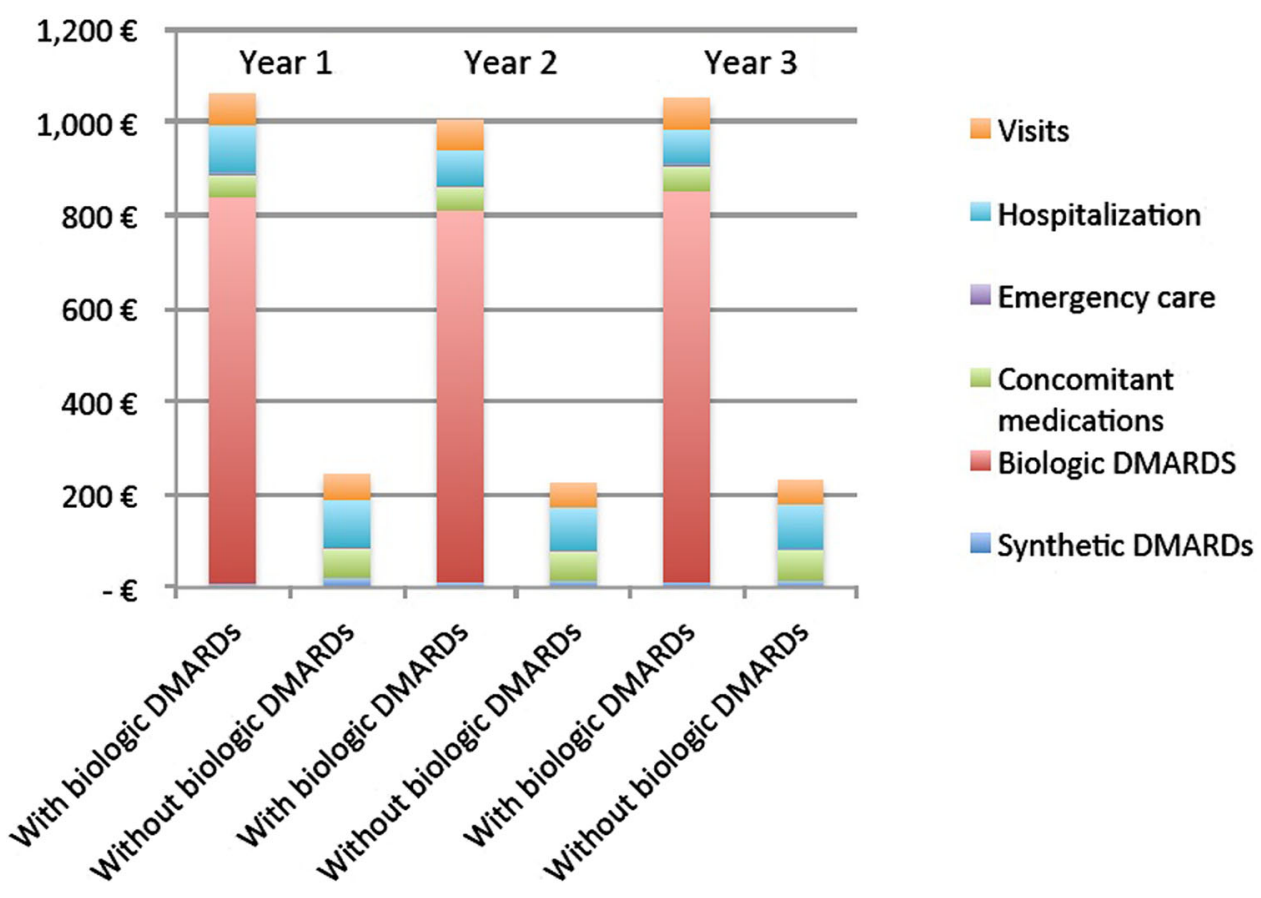

biologics. This line of reasoning could explain the high costs for concomitant medication, emergency care, hospitalizations that, compared with those related to other treatments, appear to be driving the higher total cost. From another point of view, it seems reasonable to believe that products launched in more recent years were used only in patients who received older treatments first due to the time usually necessary for new products to be considered part of the routine clinical practice. Finally, it should be considered that the route of administration (e.g. intravenous vs. subcutaneous) plays an important role in the selection of the treatment as the treating physician must take into account the characteristics of the patient (e.g., presence of disability) and the aggressiveness of the disease. We therefore suggest that the total healthcare costs of the patients treated with different biologic DMARDs in our analysis should be interpreted with caution as they were probably biased by the selection of the patients. The main limitation of the study is the lack of an analysis which adjusts for such baseline characteristics; such an adjustment was not possible given the administrative (and not clinical) nature of the database used.

\section{CONCLUSION}

The results of this study shed some light on the healthcare cost of rheumatic patients treated in Italy with biologic DMARDs. The prevalence of comorbidities in our study population was generally low and similar to the distribution reported in the general population, but our results do suggest the existence of a possible correlation between the comorbid condition and need for hospital care. The use of biologic DMARDs was generally low, with only about $13 \%$ of the cohort receiving them on the index data, but they had a major impact on the total healthcare expenditure. A substantial difference, however, seems to exists in the total costs of patients treated with different 


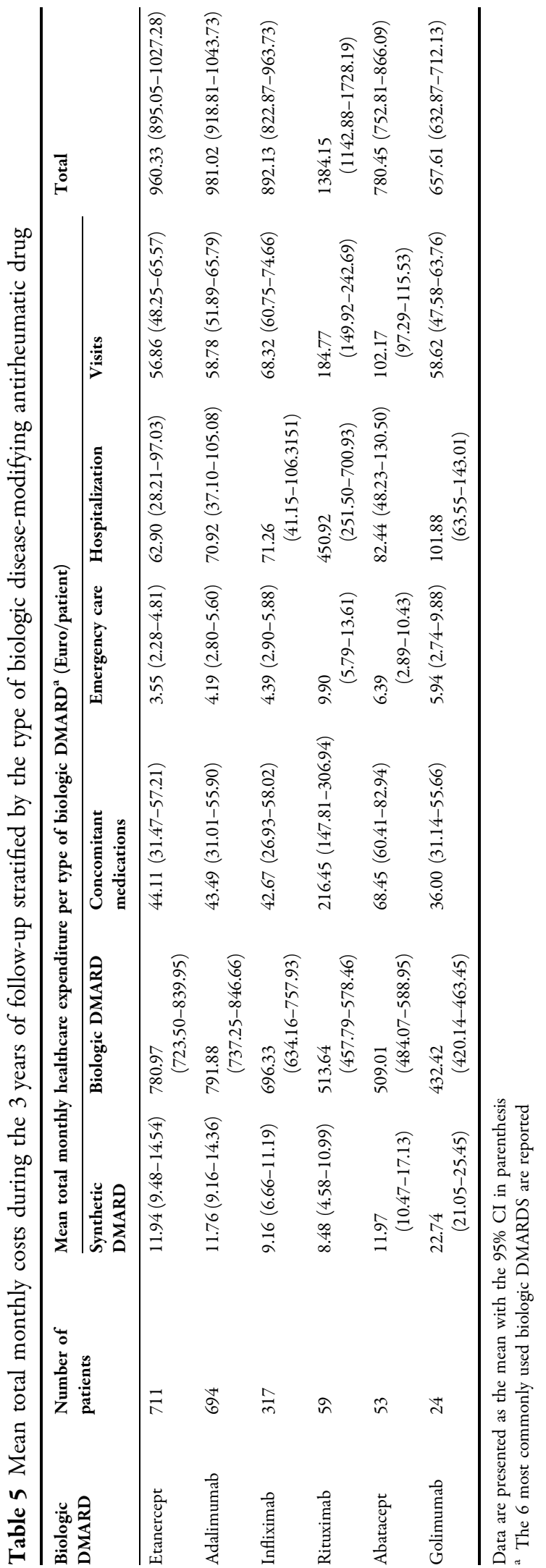

biologic DMARDS. These preliminary results need to be confirmed by further analysis.

\section{ACKNOWLEDGMENTS}

MSD, Rome, Italy, supported the development of the study through a service contract with SIHS Health Economics Consulting.

All named authors meet the International Committee of Medical Journal Editors (ICMJE) criteria for authorship for this manuscript, take responsibility for the integrity of the work as a whole, and have given final approval for the version to be published.

Disclosures. S. Iannazzo, and C. Distante work for SIHS Health Economics Consulting. MSD, Rome, Italy, supported the development of the study through a service contract with SIHS. G. Furneri, V. Berti and E. Fusaro cooperated in the development of the study and received consulting fees from SIHS. The publication of study results was not contingent on the sponsor's approval or censorship of the manuscript. All the authors have no other conflict of interest to declare.

Compliance with Ethics Guidelines. This study is based on administrative database from Regione Piemonte. As such, all data used for the study were de-identified, and no clinical or personal information was available to the authors of this study.

Open Access. This article is distributed under the terms of the Creative Commons Attribution-NonCommercial 4.0 International License (http://creativecommons.org/licenses/ by-nc/4.0/), which permits any noncommercial use, distribution, and reproduction in any medium, provided you give appropriate credit 
to the original author(s) and the source, provide a link to the Creative Commons license, and indicate if changes were made.

\section{REFERENCES}

1. Zink A, Braun J, Listing J, Wollenhaupt J. Disability and handicap in rheumatoid arthritis and ankylosing spondylitis-results from the German rheumatological database. Ger Collab Arthritis Cent J Rheumatol. 2000;27(3):613-22.

2. Borman P, Toy GG, Babaoğlu S, Bodur H, Ciliz D, Alli N. A comparative evaluation of quality of life and life satisfaction in patients with psoriatic and rheumatoid arthritis. Clin Rheumatol. 2007;26(3):330-4.

3. Büsch K, Ludvigsson JF, Ekström-Smedby K, Ekbom A, Askling J, Neovius M. Nationwide prevalence of inflammatory bowel disease in Sweden: a population-based register study. Aliment Pharmacol Ther. 2014;39(1):57-68.

4. Spector TD. Rheumatoid arthritis. Rheum Dis Clin N Am. 1990;16(3):513-37.

5. Lebwohl M. Psoriasis. Lancet. 2003;361(9364):1197-204.

6. Sieper J, Braun J. New treatment options in ankylosing spondylitis: a role for anti-TNFa therapy. Ann Rheum Dis. 2001;60[Suppl 3]:iii58-61.

7. World Health Organization (WHO). Chronic rheumatic conditions. Available at: http://www. who.int/chp/topics/rheumatic/en/. Accessed 4 Nov 2015.

8. Smolen JS, Landewe R, Breedveld FC, et al. EULAR recommendations for the management of rheumatoid arthritis with synthetic and biological disease-modifying antirheumatic drugs: 2013 update. Ann Rheum Dis. 2014;73:492-509.

9. Braun J, van den Berg R, Baraliakos X, et al. 2010 update of the ASAS/EULAR recommendations for the management of ankylosing spondylitis. Ann Rheum Dis. 2011;70:896-904.

10. Dignass A, Van Assche G, Lindsay JO, et al. The second European evidence-based Consensus on the diagnosis and management of Crohn's disease: current management. J Crohns Colitis. 2010;4:28-62.

11. Dignass A, Lindsay JO, Sturm A, et al. Second European evidence-based consensus on the diagnosis and management of ulcerative colitis part 2: current management. J Crohns Colitis. 2012;6:991-1030.

12. National Institute for Health and Care Excellence. CG153: Psoriasis: the assessment and management of psoriasis (2012). Available at: http://publications. nice.org.uk/psoriasis-cg153. Accessed 4 Nov 2015.

13. Gossec L, Smolen JS, Gaujoux-Viala C, et al. European league against rheumatism recommendations for the management of psoriatic arthritis with pharmacological therapies. Ann Rheum Dis. 2012;71:4-12.

14. Pucino F, Harbus PT, Goldbach-Mansky R. Use of biologics in rheumatoid arthritis: where are we going? Am J Health Syst Pharm. 2006;63[Suppl 4]:S19-41.

15. Kobelt G, Eberhardt K, Geborek P. TNF inhibitors in the treatment of rheumatoid arthritis in clinical practice: costs and outcomes in a follow up study of patients with RA treated with etanercept or infliximab in southern Sweden. Ann Rheum Dis. 2004;63:4-10.

16. Machado MA, Barbosa MM, Almeida AM, et al. Treatment of ankylosing spondylitis with TNF blockers: a meta-analysis. Rheumatol Int. 2013;33:2199-213.

17. Nielsen $\mathrm{OH}$, Ainsworth MA. Tumor necrosis factor inhibitors for inflammatory bowel disease. N Engl J Med. 2013;369:754-62.

18. Yost J, Gudjonsson JE. The role of TNF inhibitors in psoriasis therapy: new implications for associated comorbidities. F1000 Med Rep. 2009;1:30.

19. Mathias SD, Colwell HH, Miller DP, Moreland LW, Buatti M, Wanke L. Health-related quality of life and functional status of patients with rheumatoid arthritis randomly assigned to receive etanercept or placebo. Clin Ther. 2000;22:128-39.

20. Moreland LW, Schiff MH, Baumgartner SW, Tindall EA, Fleischmann RM, Bulpitt KJ, Weaver AL, Keystone EC, Furst DE, Mease PJ, Ruderman EM, Horwitz DA, Arkfeld DG, Garrison L, Burge DJ, Blosch CM, Lange ML, McDonnell ND, Weinblatt ME. Etanercept therapy in rheumatoid arthritis. A randomized, controlled trial. Ann Intern Med. 1999;130:478-86.

21. Italian National Institute of Statistics (ISTAT). Resident population at 01 January 2015. Available at: http://demo.istat.it/pop2015/index.html. Accessed 4 Nov 2015.

22. WHO Collaborating Centre for Drug Statistics Methodology. Anatomical therapeutic chemical classification system (ATC). Available at: http:// 
www.whocc.no/atc_ddd_index/. Accessed 4 Nov 2015.

23. Degli Esposti L, Sangiorgi D, Perrone V, Radice S, Clementi E, Perone F, Buda S. Adherence and resource use among patients treated with biologic drugs: findings from BEETLE study. Clinicoecon Outcomes Res. 2014;6:401-7. 